13

\title{
Влияние потенциала смещения и давления азотной атмосферы на структуру и свойства вакуумно-дуговых (Mo + Ti6\%Si)N покрытий
}

\author{
() В.М. Береснев, О.В. Соболь, С.В. Литовченко, А.Д. Погребняк, П.А. Сребнюк, \\ В.Ю. Новиков, Д.А. Колесников, А.А. Мейлехов, А.А. Постельник, У.С. Немченко
}

Харьковский национальный университет им. В.Н. Каразина,

61022 Харьков, Украина

T e-mail: s.lytovchenko@karazin.ua

(Поступило в Редакцию 6 сентября 2016 г.)

Методами растровой электронной микроскопии в сочетании с энергодисперсионным элементным микроанализом, рентгеноструктурного анализа, микроиндентирования исследовано влияние условий осаждения в реактивной азотной атмосфере на морфологию роста, фазовый состав, структуру и механические характеристики (микротвердость) вакуумно-дуговых многослойных покрытий, полученных испарением $(\mathrm{Ti} 6 \% \mathrm{Si})$ и Мо-катодов. Установлено, что в случае тонких нанослоев (около $7 \mathrm{~nm}$ ), сформированных из веществ, сильно отличающихся теплотой образования $(-336 \mathrm{~kJ} / \mathrm{mol}$ для TiN и $-34 \mathrm{~kJ} / \mathrm{mol}$ для MoN), в процессе формирования может происходить перераспределение атомов азота в область более сильного нитридообразующего элемента (Ti). Это приводит к расслоению с образованием нитрида TiN и металла Мо (более слабого нитридообразующего элемента). По мере увеличения давления азотной атмосферы при осаждении конденсата с $6 \cdot 10^{-4}$ до $5 \cdot 10^{-3}$ Торр происходит насыщение связей азот-металл в слоях сильных нитридообразующих элементов $\mathrm{Ti}(\mathrm{Si})$. Результатом является сначала заполнение этого соединения азотом до стехиометрического состава, а затем и насыщение азотом второй системы слоев на основе молибдена с образованием фазы $\gamma-\mathrm{Mo}_{2} \mathrm{~N}$. Повышение потенциала смещения $U_{\mathrm{SP}}$ от -100 до $-200 \mathrm{~V}$ интенсифицирует в тонких слоях процессы перемешивания с образованием твердого раствора ( $\mathrm{Ti}, \mathrm{Si}, \mathrm{Mo}) \mathrm{N}$ и приводит к понижению микротвердости с 37 до $32 \mathrm{GPa}$.

DOI: 10.21883/JTF.2017.05.44455.2030

\section{Введение}

Развитие современных технологий предъявляет повышенные требования к свойствам поверхности деталей и конструкций. Проблему достижения необходимых функциональных свойств во многих случаях можно решить путем осаждения сравнительно тонких (до $10 \mu \mathrm{m}$ ) многоэлементных покрытий [1-3]. При вакуумно-дуговом методе их получения наиболее высокие свойства (прежде всего механические) на сегодняшний день реализованы в многоэлементных покрытиях на основе нитридов переходных металлов [4-8].

Исследование состава многоэлементных покрытий, закономерностей формирования их структуры, напряженного состояния, а также связи этих параметров с физико-механическими характеристиками является основой интенсивно развивающегося в последние годы научно-практического направления - структурной инженерии [9-11]. Такие исследования также являются базой для развития современных представлений о физических процессах формирования нанокристаллических твердых покрытий в сильнонеравновесных условиях осаждения вакуумно-плазменных потоков [12-14]. В этой связи для осуществления необходимого управления наноструктурным состоянием покрытий эффективным и достаточно часто используемым является метод формирования многослойных структур с наноразмерным периодом $[15,16]$. При формировании таких композитных структур образуется кристаллитная структура с раз- личной структурной неравновесностью, дефектностью, перераспределением элементов как в объеме, так и в приграничных областях [17-20].

Целью работы является выяснение закономерностей формирования фазового состава, структурного состояния многослойных нанокомпозитных нитридных конденсатов, полученных при вакуумно-дуговом испарении в азоте двух мишеней состава $\mathrm{Ti}+\mathrm{Si}$ и $\mathrm{Mo}$, а также исследование влияния структурно-фазового состояния конденсата на механические свойства композита. Многослойность конденсата достигалась вращением подложки в процессе формирования покрытия.

\section{Образцы и методика исследований}

Образцы были получены вакуумно-дуговым методом на модернизированной установке „Булат-6“ [21]. Давление рабочей (азотной) атмосферы при осаждении составляло $(0.6-5) \cdot 10^{-3}$ Torr. Осаждение покрытий осуществлялось из двух источников (состав первого - $\mathrm{Ti}+6 \% \mathrm{Si}$, второго - Мо) при непрерывном вращении закрепленных на подложках образцов со скоростью $8 \mathrm{rpm}$, что позволяло за $1 \mathrm{~h}$ получать слой толщиной около $7 \mathrm{~nm} \mathrm{c}$ общим числом слоев 960 (или 480 бислойных периодов).

Кремний предварительно вводился в титановую мишень, а оттуда попадал в покрытие в количестве 0.8-1 at.\% для усиления нитридообразования в слоях $\mathrm{TiN}$ и получения композиции (TiSi)N. B процессе оса- 

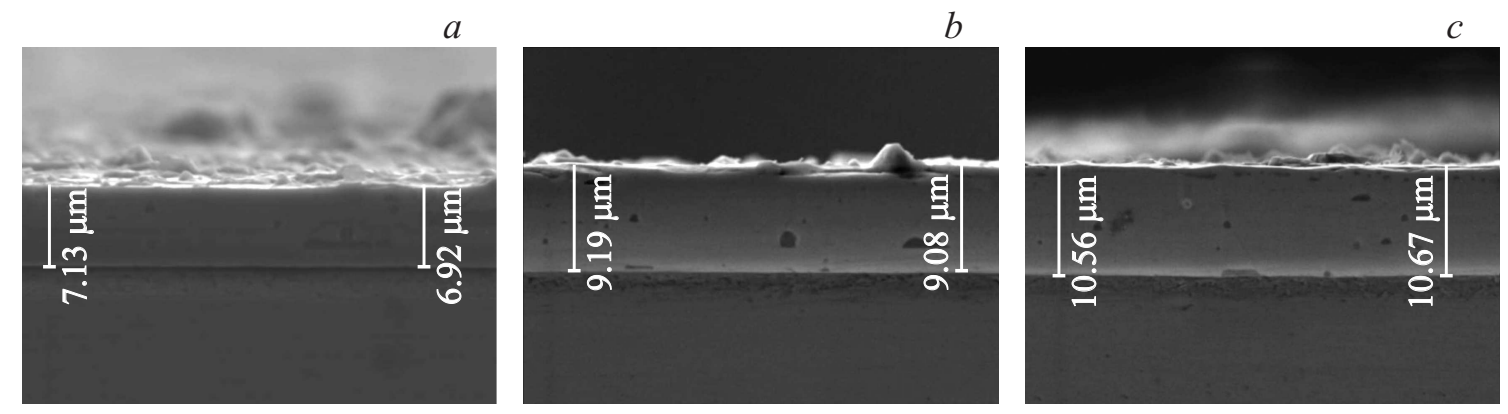

Pис. 1. Морфология сечения покрытий, полученных при $U_{\mathrm{SP}}=-200 \mathrm{~V} P_{\mathrm{N}}=6.0 \cdot 10^{-4}$ Torr $(a), U_{\mathrm{SP}}=-200 \mathrm{~V}, P_{\mathrm{N}}=$ $=5.0 \cdot 10^{-3}$ Torr $(b), U_{\mathrm{SP}}=-100 \mathrm{~V}, P_{\mathrm{N}}=5.0 \cdot 10^{-3} \operatorname{Torr}(c)$.

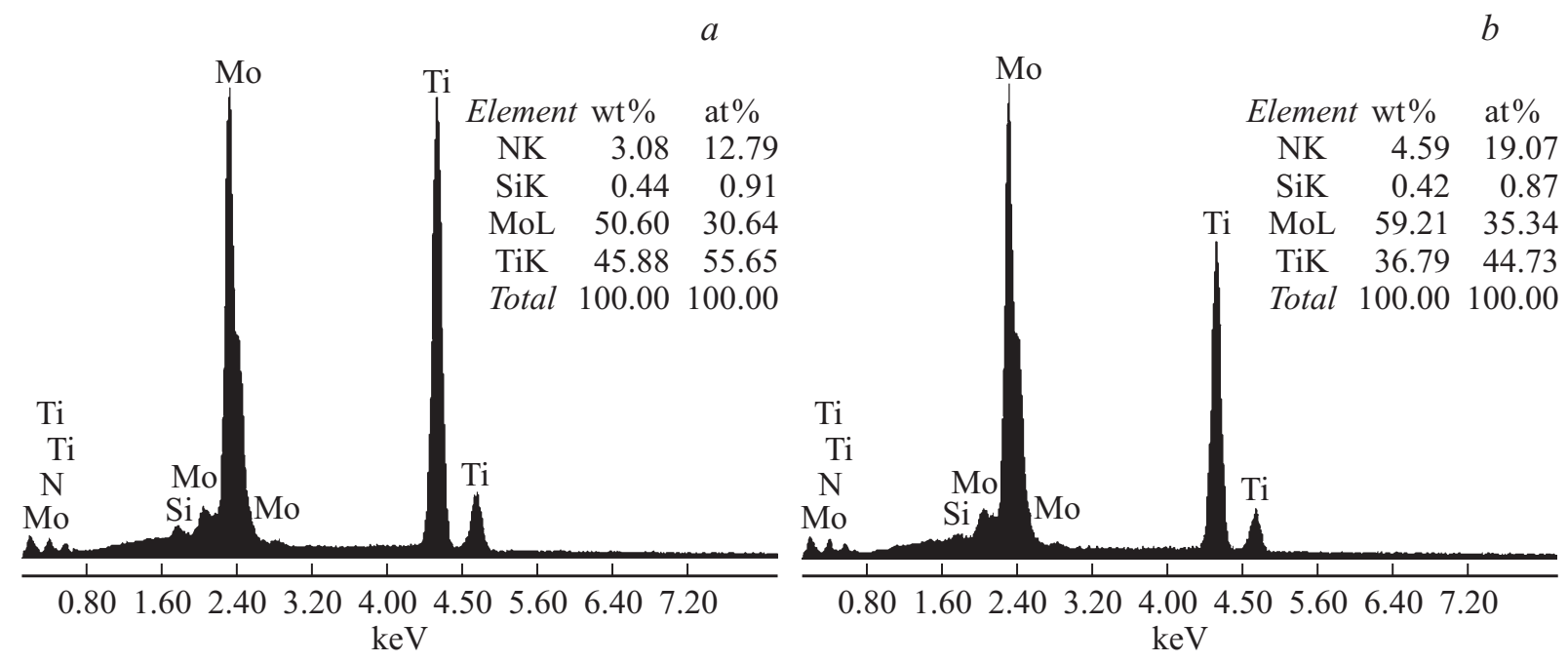

Pис. 2. Энергодисперсионные спектры и элементный состав покрытий, полученных при $U_{\mathrm{SP}}=-100 \mathrm{~V} . a-P_{\mathrm{N}}=6.0 \cdot 10^{-4}$ Torr, $b-P_{\mathrm{N}}=5.0 \cdot 10^{-3}$ Torr.

ждения на подложки подавался постоянный отрицательный потенциал $U_{\mathrm{SP}}$ величиной -100 и $-200 \mathrm{~V}$.

Структурно-фазовый анализ проводили методом рентгеновской дифрактометрии в излучении $\mathrm{Cu}-k_{\alpha}$ на установке ДРОН-4. Разделение профилей на составляющие осуществлялось с использованием пакета программ „NewProfile“ (разработка НТУ „ХПИ“). Микротвердость покрытий определяли на приборе DM-8 при нагрузке на индентор $50 \mathrm{~g}$.

Элементный состав покрытий определяли по спектрам характеристического рентгеновского излучения, генерируемого электронным пучком в растровом электронном микроскопе FEI Nova NanoSEM 450. Спектры получали на энергодисперсионном спектрометре рентгеновского излучения системы PEGASUS фирмы EDAX, установленном в микроскопе.

\section{Результаты и их обсуждение}

Анализ морфологии бокового сечения покрытий, полученных во всем исследуемом интервале изменения давления рабочей азотной атмосферы $P_{\mathrm{N}}$ и постоянного потенциала смещения на подложке $U_{\mathrm{SP}}$, показал их достаточно высокую однородность и низкую дефектность по толщине (рис. 1). Понижение давления $P_{\mathrm{N}}$ (рис. $\left.1, a\right)$ и увеличение потенциала $U_{\mathrm{SP}}$ (рис. $\left.1, b\right)$ при осаждении приводит к уменьшению толщины покрытия, что может быть следствием интенсификации процессов вторичного распыления [4]. Эти же процессы обусловливают и изменения элементного состава.

Анализ энергодисперсионных спектров (рис. 2) и их обобщение (рис. 3) свидетельствуют, что относительное обогащение покрытия наиболее сильным нитридообразующим элементом Ті происходит при наименьшем давлении азота. В этих условиях вероятность столкновения атомов в межэлектродном промежутке с потерей энергии мала, и в результате бомбардировки высокоэнергетичными частицами наиболее интенсивно протекают процессы вторичного распыления [4,11].

Повышение потенциала смещения $U_{\mathrm{SP}}$ от -100 до $-200 \mathrm{~V}$ усиливает эффект селективного обогащения покрытия атомами Ті (рис. $3, b$ ). Отметим, что содержание $\mathrm{Si}$, добавляемого для усиления нитридообразования в покрытии, при всех используемых в работе режимах 

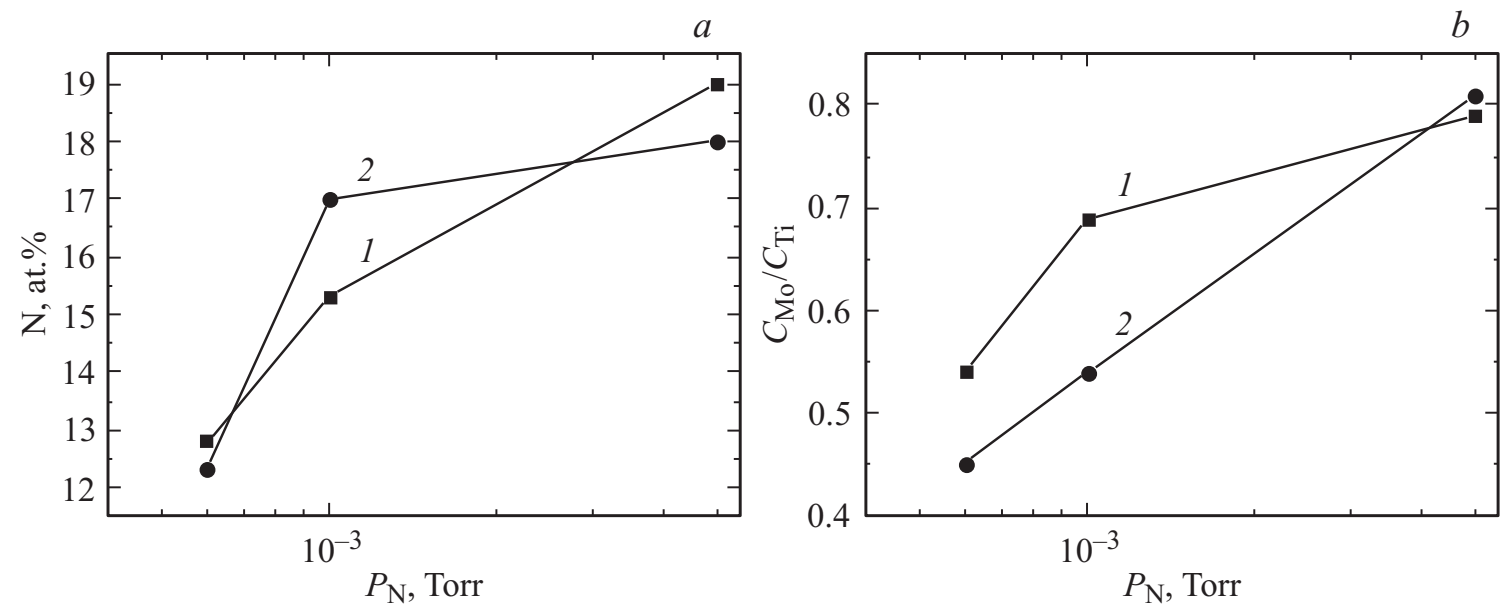

Рис. 3. Содержание азота $(a)$ и соотношение $C_{\mathrm{Mo}} / C_{\mathrm{Ti}}(b)$ при разном давлении азота в процессе осаждения покрытий при $U_{\mathrm{SP}}=-100 \mathrm{~V}(1)$ и $U_{\mathrm{SP}}=-200 \mathrm{~V}(2)$.
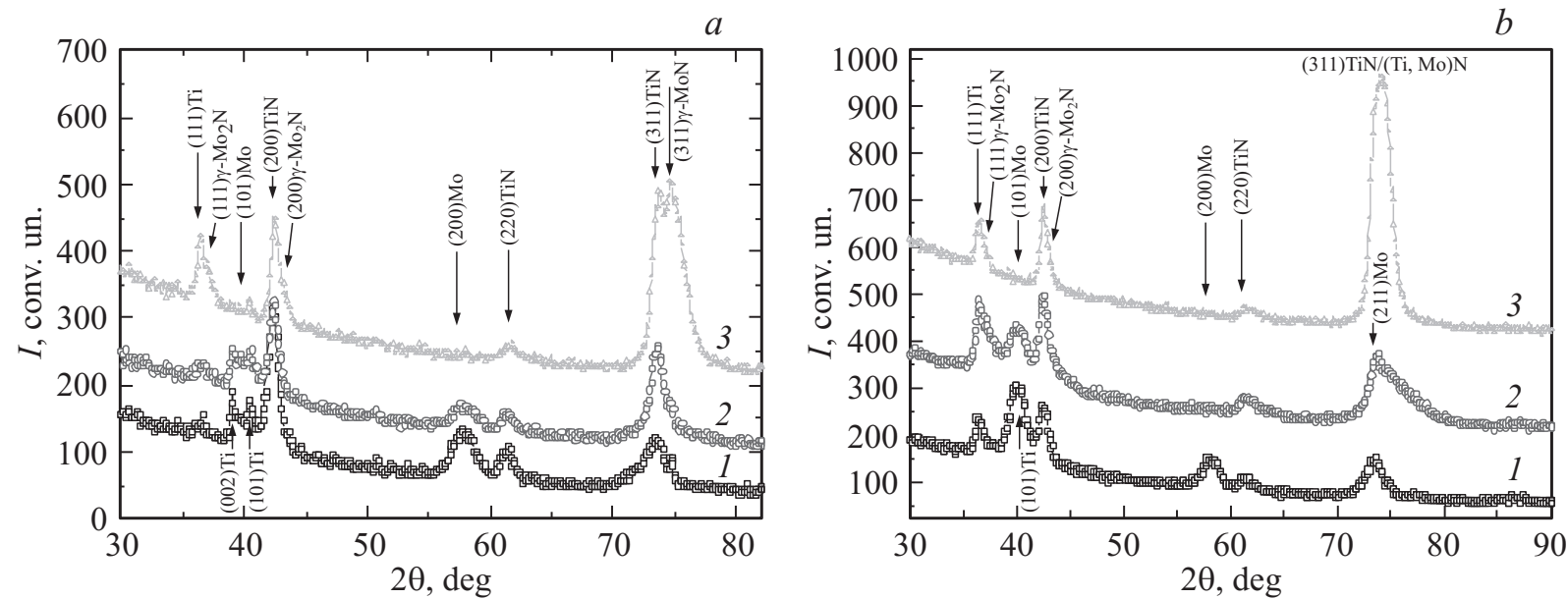

Рис. 4. Дифракционные спектры покрытий, полученных при $P_{\mathrm{N}}=6.0 \cdot 10^{-4}(1), 1.0 \cdot 10^{-3}(2), 5.0 \cdot 10^{-3}(3)$ Torr, $U_{\mathrm{SP}}=-100(a)$ и $-200 \mathrm{~V}(b)$.

не превышало 1 at.\% (от 0.8 до 1 at.\%). Ожидалось, что такое небольшое содержание $\mathrm{Si}$ в покрытии не должно было приводить к расслоению с образованием фазы $\mathrm{SiN}_{x}$ [1]. Это и подтвердил рентгеновский анализ: на дифракционных спектрах (рис. 4) пики, соответствующие этой фазе, не зафиксированы.

Содержание азота, как и ожидалось, минимально в случае получения покрытий при наименьшем давлении азота $P_{\mathrm{N}}=6.0 \cdot 10^{-4}$ Torr. Анализ рентгеновских спектров показывает (рис. 4), что азот связывается в первую очередь с сильным нитридообразующим элементом титаном (и растворенным в нем кремнием), при этом формируется нитрид $\mathrm{Ti}(\mathrm{Si}) \mathrm{N}$ с преимущественной ориентацией кристаллитов с осью [100]. Также на спектрах выявляются $\alpha$-Ті и Мо, где содержание азота настолько мало, что образование нитридных фаз невозможно.

Повышение давления азота при осаждении ожидаемо увеличивает его содержание в покрытиях (рис. 3,a), кроме этого, растет и содержание молибдена, ко- торый при наибольшем из примененных давлений $P_{\mathrm{N}}=5.0 \cdot 10^{-3}$ Torr выявляется на спектрах уже в качестве изоструктурной с нитридом титана фазы $\gamma-\mathrm{Mo}_{2} \mathrm{~N}$.

Коромысло с держателями образцов вращается, происходит непрерывное перемещение подложки от одного источника к другому [7]. При этом образуются тонкие слои конденсата (около $7 \mathrm{~nm}$ ). Более высокая теплота образования нитрида титана приводит к перераспределению атомов азота в покрытии. При низком давлении азота в процессе осаждения азот мигрирует от слоев Мо к слоям Ті. Процесс усиливается наличием атомов $\mathrm{Si}$ в $\mathrm{Ti}$, и в результате в пленке формируются слои $\mathrm{TiN}$ и Мо.

Только при большом давлении азота $\left(5.0 \cdot 10^{-3}\right.$ Torr $)$, когда фаза TiN полностью насыщается азотом, наряду с образованием нитрида TiN образуется нитрид $\gamma-\mathrm{Mo}_{2} \mathrm{~N}$.

Характерной особенностью структурного состояния полученных в указанных условиях нитридных

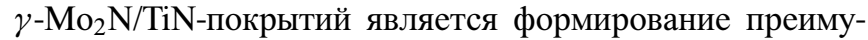


щественной ориентации кристаллитов с осью [311], перпендикулярной плоскости роста, что следует из относительного повышения интенсивности рефлексов на спектрах 3 (рис. 3). Формирование такого типа текстуры отмечено ранее только для покрытий $\gamma-\mathrm{Mo}_{2} \mathrm{~N}$ [11]. Таким образом, структура слоев $\gamma-\mathrm{Mo}_{2} \mathrm{~N}$, формируемых при давлении $P_{\mathrm{N}}=5.0 \cdot 10^{-3}$ Torr, является доминирующей с точки зрения образования текстуры.

При меньшем потенциале смещения $U_{\mathrm{SP}}=-100 \mathrm{~V}$ происходит формирование двух слоев с различными периодами решетки $(0.4258 \mathrm{~nm}$ для TiN и $0.4209 \mathrm{~nm}$ для $\left.\gamma-\mathrm{Mo}_{2} \mathrm{~N}\right)$. Это проявляется на дифракционном спектре 3 (рис. 3,a) в виде двух разрозненных рефлексов с соответствующим положением. При большем потенциале смещения $\left(U_{\mathrm{SP}}=-200 \mathrm{~V}\right)$ при сохранении того же типа текстуры [311] формируется один общий пик с положением, соответствующим периоду решетки $0.4232 \mathrm{~nm}$. Этот пик можно связать с образованием твердого раствора $(\mathrm{Ti}, \mathrm{Mo}) \mathrm{N}$ в результате радиационно-стимулированного перемешивания атомов под действием высокоэнергетичных ионов, бомбардирующих растущее покрытие.

Анализ влияния элементно-структурного состояния покрытий на их твердость как наиболее универсальную характеристику механических свойств показал, что образование перемешанных слоев при большом потенциале $U_{\mathrm{SP}}=-200 \mathrm{~V}$ снижает твердость покрытий до величины $32-33 \mathrm{GPa}$. Образование двуслойного состояния при меньшем потенциале $U_{\mathrm{SP}}=-100 \mathrm{~V}$ при прочих равных условиях формирования покрытия позволяет повысить твердость до $37.3 \mathrm{GPa}$.

\section{Выводы}

При формировании многослойных покрытий с тонкими (около $7 \mathrm{~nm}$ ) слоями высокая подвижность легких азотных атомов в процессе осаждения приводит к их направленной миграции в области с сильными нитридообразующими элементами и формированию композиции нитрид/металл.

По мере увеличения давления рабочей азотной атмосферы при осаждении интенсифицируется насыщение связей азот-металл в слоях сильных нитридообразующих элементов $\mathrm{Ti}(\mathrm{Si})$. В результате этого сначала происходит заполнение нитрида титана азотом до стехиометрического состава, после чего азот насыщает и вторую систему слоев (пленки молибдена) с образованием фазы $\gamma-\mathrm{Mo}_{2} \mathrm{~N}$.

Повышение потенциала смещения $U_{\mathrm{SP}}$ от -100 до $-200 \mathrm{~V}$ сопровождается интенсификацией процессов перемешивания с образованием твердого раствора $(\mathrm{Ti}, \mathrm{Si}, \mathrm{Mo}) \mathrm{N}$ и приводит к понижению твердости от 37 до $32 \mathrm{GPa}$.

\section{Список литературы}

[1] Nanostructured coatings / Ed. by Albano Cavaleiro, Jeff Th.M.De Hosson. N. Y.: Springer-Verlag, 2006. 648 p.

[2] Погребняк А.Д., Дробышевская А.А., Береснев В.М., Кылышканов М.К., Кирик Е.В., Дуб С.Н., Комаров Ф.Ф., Шипиленко А.П., Тулеушев Ю.Ж. // ЖТФ. 2011. Т. 81. Вып. 7. С. 124-131.

[3] Sobol' O.V., Grigorjev O.N., Kunitsky Yu.A., Dub S.N., Podtelezhnikov A.A., Stetsenko A.N. // Sci. of Sintering. 2006. Vol. 38. P. 63-72.

[4] Sobol' O.V., Andreev A.A., Stolbovoi V.A., Fil'chikov V.E. // Technical Phys. Lett. 2012. Vol. 38. N 2. P. 168-171.

[5] Munz W.D. // Vac. Sci. Technol. A. 1986. Vol. 4. P. $2717-$ 2725.

[6] Погребняк А.Д., Шиак А.П., Азаренков Н.А., Береснев В.М. // УФН. 2009. Т. 179. № 1. С. 36-64.

[7] Beresnev V.M., Sobol O.V., Toryanik I.N., Meylekhov A.A., Nyemchenko U.S., Turbin P.V, Yakushchenko I.V., Lisovenko M.O. // J. Nano- and Electronic Phys. 2014. Vol. 6. N 1. P. 01030 (3 pp).

[8] Hua M., Maa H.Y., Li J., Mok C.K. // Surf. Coat. Technol. 2006. P. 3612-3625.

[9] Sobol' O.V. // Phys. Sol. Stat. 2007. Vol. 49. N 6. P. 1161-1167.

[10] Игнатенко П.И. // ЖТФ. 2011. Т. 81. Вып. 2. С. 108-112.

[11] Sobol' O.V. // Phys. Metals and Metallography. 2001. Vol. 91. N 1. P. 60-67.

[12] Knotek O., Bohmer M., Leyendecker T., Jungblut F. // Mater. Sci. Eng. AW. 1988. Vol. 6. P. 481-488.

[13] Sobol' O.V., Andreev A.A., Grigoriev S.N., Gorban' V.F., Volosova S.N., Aleshin S.V., Stolbovoy V.A. // Problems of Atomic Science and Technology. 2011. N 4. P. 174-177.

[14] Андриевский Р.А. Синтез и свойства пленок фаз внедрения // Успехи химии. 1997. Т. 66. № 1. С. 57-77.

[15] Соболь О.В., Андреев А.А., Горбань В.Ф., Столбовой В.А., Мейлехов А.А., Постельник А.А. // ЖТФ. 2016. Т. 86. Вып. 7. С. 100-103.

[16] Hakansson G, Sundgren J.E., Mcintyre D., Greene J.E., Munz W.D. // Thin Solid Films. 1987. Vol. 153. P. 55-65.

[17] Metastable, Mechanically Alloyed and Nanocrystalline Materials / By ed. R. Shulz. Zurich: Transtech Publications, 1996. Part 1. 263 p.

[18] Benia H.M., Guemmaz M., Schmerber G., Mosser A., Parlebas J.-C. // Appl. Surface Sci. 2002. N 200. P. 231-238.

[19] Heinrich S., Schirmer S., Hirsch D., Gerlach J.W., Manova D., Assmann W., Mändl S. // Surface \& Coatings Technology. 2008. Vol. 202. P. 2310-2313.

[20] Mayrhofer P.H., Mitterer Ch., Wen J.G., Greene J.E., Petrov I. // Appl. Phys. Lett. 2005. Vol. 86. N 13. P. 131909 (3).

[21] Аксенов И.И., Андреев А.А., Белоус В.А., Стрельницкий B.E., Хороших В.M. Вакуумная дуга: источники плазмы, осаждение покрытий, поверхностное модифицирование. Киев: Наукова думка, 2012. 726 с. 